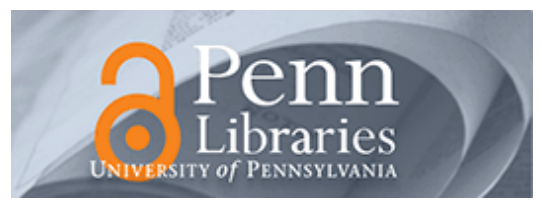

University of Pennsylvania Working Papers in Linguistics

Volume 6

2000

\title{
The Effect of Thematic Roles on Pronoun Use and Frequency of Reference Continuation
}

Jennifer E. Arnold

University of Pennsylvania

Follow this and additional works at: https://repository.upenn.edu/pwpl

\section{Recommended Citation}

Arnold, Jennifer E. (2000) "The Effect of Thematic Roles on Pronoun Use and Frequency of Reference Continuation," University of Pennsylvania Working Papers in Linguistics: Vol. 6 : Iss. 3 , Article 2.

Available at: https://repository.upenn.edu/pwpl/vol6/iss3/2

This paper is posted at ScholarlyCommons. https://repository.upenn.edu/pwpl/vol6/iss3/2

For more information, please contact repository@pobox.upenn.edu. 
The Effect of Thematic Roles on Pronoun Use and Frequency of Reference Continuation 


\title{
The Effect of Thematic Roles on Pronoun Use and Frequency of Reference Continuation*
}

\author{
Jennifer E. Arnold
}

\section{Introduction}

Research has shown that pronoun resolution is influenced by the thematic roles of discourse referents (e.g., Garnham et al. 1996, Garvey and Caramazza 1974, McDonald and MacWhinney 1995, Stevenson et al. 1994). For example, the pronouns in (1a) and (b) are more naturally interpreted as coreferential with the stimulus referent-i.e., the entity that occurs in the stimulus role in the first clause, in this case, John.
a. $\frac{\text { John }}{\text { stimulus }}$
amazed
Bill
because he...
b. $\underline{\text { Bill }}$
admired
experiencer
experiencer
$\frac{\text { John }}{\text { stimulus }}$
because he...

This bias toward John has been attributed to the 'Implicit Causality' of the verb. That is, John is implicitly understood at the cause of the event denoted by the verb (e.g., Au 1986, Brown and Fish 1983), which influences the interpretation of the ambiguous pronoun he.

There are several questions that arise from this line of research. First, does the same factor influence the speaker's choices in reference form? Evidence suggests that it would: off-line data from a sentence-completion study shows that thematic roles influence choices in referring forms in writing (Stevenson et al. 1994), and pronoun use is generally influenced by the same factors as pronoun comprehension (Amold 1998). In this paper I will focus on goal and source roles in verbs of transfer, like give or receive, and confirm that speakers use pronouns for subsequent reference to goal entities more often than for source entities.

More important is the second question: Why do thematic roles influence referent accessibility in the way they do? Previous research on implicit cau-

* This research was funded by a Graduate Research Opportunity Grant from Stanford University. The data are also presented in Chapter 4 of my Ph.D. dissertation, "Reference Form and Discourse Patterns" (Stanford University, 1998). I gratefully acknowledge comments and advice from Thomas Wasow, Herb Clark, Eve Clark, Maryellen MacDonald, and two anonymous reviewers. Many thanks to Carie Lemack for her help in designing and executing the experiment. Any shortcomings of this paper are naturally my own. 
sality and thematic role biases have left this question relatively unanswered. Most researchers have accounted for pronoun biases in sentences like (1) in terms of readers' interpretations of the implicit cause of the event (e.g., Garvey and Caramazza 1974, McDonald and MacWhinney 1995). However, implicit causality only impacts pronoun resolution when the following clause is introduced with a because connector. Therefore, an implicit causality account is not a general explanation.

Stevenson et al. (1994) provide a more sophisticated account of thematic role biases, suggesting that with verbs that denote events, readers by default focus on the consequence of the event, but with stative verbs (that have no event structure), readers by default focus on the cause. In addition, these biases can be enhanced or reversed in the presence of connectors like because or so. However, a limitation of this account is that it depends on a set of rules for specific verbs or verb classes, e.g., "focus on the consequences unless you see the connector because." Furthermore, it suggests that referent accessibility is driven by default processing assumptions, which would suggest that processing preferences are relatively homogeneous. By contrast, I will present results that are not consistent with an account driven by defaults.

In this paper I will build on Stevenson et al.'s account, proposing a more general explanation of how and why thematic role information influences referent accessibility. I will present results from a story-continuation experiment and a corpus analysis which suggest that the bias towards goals is linked to a more general tendency for speakers to frequently refer to goal entities.

\section{Goal and Source in Verbs of Transfer}

The studies in this paper investigate goal and source roles in transfer verbs. These verbs are advantageous because there are some verbs in which the subject is the source (e.g., send) and some verbs in which the subject is the goal (e.g., receive). This feature is important because research has shown that reference form is highly sensitive to the grammatical role of the antecedent (e.g., Arnold 1999, Gordon et al. 1993, Stevenson et al. 1994). Therefore, the effect of other characteristics such as thematic roles may only be observable while controlling for grammatical role.

In this study I am concerned with how referent accessibility is influenced by the thematic roles played by discourse entities in the preceding discourse. Therefore, I am interested in how speakers choose referring forms for entities that were the goal or the source of the preceding clause. To refer to these entities, I will use the terms 'goal-referent' or 'source-referent.' Similarly, I will use the terms 'subject-referent' or 'object-of-PP-referent' to refer to those same entities in terms of the grammatical function of the last phrase used to refer to them. 
Past research suggests that goal-referents are more accessible than sourcereferents (Stevenson et al. 1994, Stevenson and Urbanowicz 1995, Wilson and Stevenson 1999). The participants in Stevenson et al.'s (1994) sentencecompletion study interpreted ambiguous pronouns as referring to goalreferents more often than to source-referents, and in the condition where the pronoun was not supplied, participants referred to the goal more than to the source. Wilson and Stevenson (1998) replicated these findings, and also showed that pronouns referring tooal entities are read faster than pronouns referring to source entities.

Further support comes from Stevenson and Urbanowicz's (1995) selfpaced reading experiment, in which they recorded the time it took participants to read anaphors with goal- or source-referents. Although their discussion did not focus on the difference in reading times for pronouns and full names, their results can be used to investigate whether names are read faster than pronouns, and if so, whether this difference varies depending on the thematic role of the antecedent. Using their data, I calculated the difference between the reading times for pronouns and names (= (average RT for pronouns)(average RT for names)), such that a positive difference indicates a shorter reading time for names. Figure 1 presents the average differences in reading times separately for NP1 antecedents (subject antecedents) and NP2 antecedents (object antecedents).

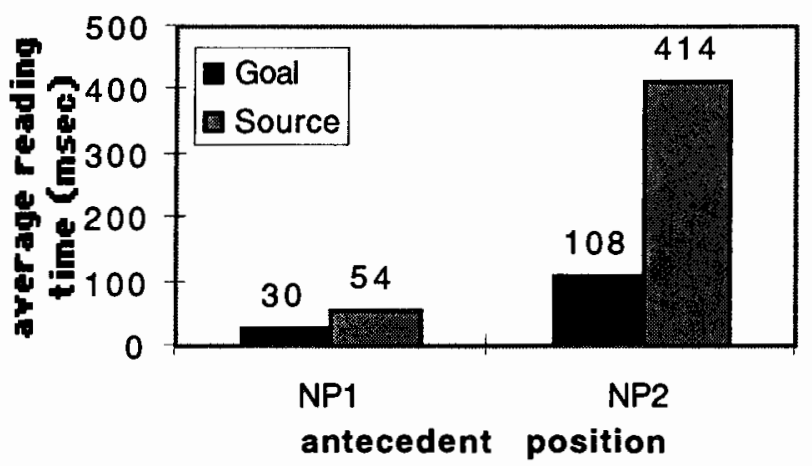

Figure 1. The extent to which reading times were shorter for names than pronouns, in msec. (Calculated from data in tables (2) and (4), Stevenson and Urbanowicz 1995).

These data show that participants read names faster than pronouns in all conditions, which could be termed a 'name advantage.' However, there was a greater name advantage for source-referents than goal-referents, for both NP1 
and NP2 antecedents. Put another way, pronouns were read relatively faster for goal-referents than source-referents, suggesting that the goal-referent was more accessible. At the same time, thematic role interacted with order of mention, such that the advantage for goal referents was stronger for object-ofPP-referents.

Thus, there is good reason to think that goal-referents are more accessible than source-referents, at least at the moment that referring forms are encountered. But why does this pattern exist?

I performed the experiment described below to investigate two questions. First, are speakers' on-line choices of referring forms indeed influenced by thematic role? Second, can the effects of thematic roles be explained in terms of more general patterns of reference continuation? That is, do speakers tend to continue talking about goal- or source entities more frequently?

\section{Experiment: Goals and Sources}

\subsection{Method}

The methodology used in this experiment was an oral story-continuation, conducted in the language laboratory at Stanford University. Each participant sat in a cubicle outfitted with a tape recorder and headset with a microphone and earphones. The stimuli were provided in written form, with several spaces between each item to prevent participants from reading the following item while completing the current one. The first two sentences in each stimulus item set the context for the story; the last sentence contained a verb with goal and source arguments. Examples are in (2) and (3).

(2) There was so much food for Thanksgiving, we didn't even eat half of it. Everyone got to take some food home. Lisa gave the leftover pie to Brendan....

(3) I hate getting sick. It always seems like everyone gets sick as soon as it's vacation. Marguerite caught a cold from Eduardo two days before Christmas. ...

Participants were asked to read these stories aloud into a tape recorder and add a natural continuation sentence to the story at the end.

This method combines comprehension and production processes. Although the task was to produce an utterance, it required participants to comprehend the stories before providing a continuation. Of particular importance is that their responses were made on the basis of the mental representations they developed while reading the story. In that sense, their 
responses reflect the accessibility of discourse entities that resulted from their comprehension of the story.

This method allowed me to investigate several things. First, participants were not restricted in the type of continuation they added, except that it had to be a new sentence, rather than a continuation of the last one. This freedom meant that their responses provided information about how they would tend to continue the story, and allowed me to investigate which character they would mention first. Second, I could analyze whether participants used pronouns more often for goal or source characters.

A third question that I asked in this study was how the participants' continuations would be influenced by the relationship between their continuation sentence and the stimulus story. That is, did participants produce continuations that expressed the cause of the preceding event, a subsequent event, or something else? I considered the participants' continuation to be an indicator of their mental representation as it was at the end of the stimulus story. Therefore, if a participant provided a causal continuation, it signaled that the causal relationship was most activated at the end of the stimulus story.

The method I used had other advantages as well. Since the task was oral, rather than written, it reflected on-line processes. In contrast, a written storycontinuation methodology would have allowed participants to reflect upon the story and their continuations. Also, in contrast with rating questionnaires, this method makes it possible to exclude an item when it was clear that the participant had not understood the story as intended (for example, when a name was interpreted with a different gender than the one intended).

\subsection{Materials}

Each stimulus item consisted of a three-sentence story like (2) and (3) above. The first two sentences provided the context, and did not contain individual references to either of the characters introduced in the third sentence. The third sentence included either a goal-source verb or a source-goal verb; all the verbs used are provided in (4).

(4) Verbs used in the story-continuation experiment

a. Source-Goal verbs: bring, give, hand, loan, offer, pass, pay, rent, sell, send, show, teach (used twice), tell, throw, toss

b. Goal-Source verbs: accept, borrow, bought, catch (used twice), get (used twice), grab, hear, inherit, learn, purchase, receive, rent, snatch, take 
All verbs were used in a prepositional frame. Source-goal verbs are commonly used in both prepositional and double-object constructions ('Cynthia taught the lambada to Sean' / 'Cynthia taught Sean the lambada'). For these verbs I only included prepositional constructions. This was to maintain consistency with the goal-source verbs, where the source argument must appear as an object of preposition, as in 'Annette caught a ride from Scott'. This consistency was particularly important because the choice between the double object and prepositional constructions is partly driven by the discourse status of the referents (Arnold et al., in press).

In the third sentence of each story, two human characters were introduced by first names. These two characters filled the source and goal roles in the event. The names used were ones that are almost always associated with only one gender. In all cases, the two characters were of opposite gender. The theme argument was always inanimate. In half the items, the theme argument occurred as a definite NP, in half as an indefinite NP.

Unlike other implicit causality studies, I did not include any conditions with overt connectors like because or so. Their absence meant that the relation of the continuation sentences was driven by other factors. The purpose of this study was not to discover exactly what those were. Instead, I just wanted to know whether participants would choose to refer to source- or goalreferents more often, depending on the role of the continuation sentence.

A total of 16 sentences were constructed with each type of verb. Each participant saw all 32 items (Appendix A). They were combined with 24 items belonging to another experiment (Experiment 2 in Arnold 1999), such that items for each experiment served as distractors for the other. The items from the other experiment also had three sentences and used proper names, but followed a different structure from the current experimental items.

\subsection{Participants}

Sixteen native speakers of English from the Stanford community participated in this and another experiment in exchange for $\$ 7$. The approximate time needed to complete both experiments was forty-five minutes. Native speaker was defined as having started learning English by 5 years of age.

\subsection{Results}

The continuations for each item were tape-recorded and transcribed. Thirtyfive continuations were excluded from the analysis. Reasons for exclusion included continuing the last sentence rather than beginning a new one $(n=13)$, adding a nonsensical or ambiguous continuation $(n=6)$, saying nothing at all $(n=3)$, experimenter error $(n=8)$, or interpreting the name of one of the characters with the unintended gender $(n=5)$. For example, the name Ali was 
intended as a female name, but some participants read the name Ali as a male name, with an accent on the second syllable. Examples of scorable participant continuations are shown in Table 1.

Stimulus: There was so much food for Thanksgiving, we didn't even eat half of it. Everyone got to take some food home. Lisa gave the leftover pie to Brendan...

- Brendan loved pie and cakes and all manner of sweet things but didn't know how to bake.

- He needed it the most since he was living off campus and didn't have access to food.

- I got the turkey and the stuffing, yum!

- She gave all the leftover turkey to me, and I asked if I could have the stuffings too, but she said don't be greedy, she gave the stuffings to her sister.

Stimulus: I hate getting sick. It always seems like everyone gets sick as soon as it's vacation. Marguerite caught a cold from Eduardo two days before Christmas. . .

- Unfortunately, Marguerite was sick on Christmas day.

- She was headed for the Bahamas, and it was tough.

- Eduardo gave it to me . . and so I was sick over the entire holiday.

- And they were both in bed for the holiday.

Table 1. Example responses from the story-continuation experiment.

I was only interested in the frequency of referring to the goal and source characters, so references to other people or things were not included in the analysis. This left 346 continuations that could be analyzed.

For each item, I only considered the first continuation sentence, coding three things. First, I identified which character or object from the previous utterance was referred to first, if any. Second, I looked at how this character was referred to-with a pronoun or with a name. The rationale behind this procedure was to determine which of the two characters was considered more relevant to the following discourse, and to see how that character was referred to.

I also looked at a third factor: type of continuation sentence. I coded each response in terms of it's contribution to the discourse: a) specifying the cause, b) specifying the consequence, c) elaborating or developing the idea of 
the last sentence further, or d) describing a related yet independent fact or event. Table 2 shows examples of each type.

\begin{tabular}{l|l} 
RELATION & EXAMPLE \\
\hline cause & $\begin{array}{l}\text { The U2 concert was sold out a week before the show. } \\
\text { Scalpers were selling tickets for ridiculous prices. Fortu- } \\
\text { nately Rafael got a ticket from Gabrielle. Gabrielle's } \\
\text { friend Phil couldn't make the concert. }\end{array}$ \\
consequence & $\begin{array}{l}\text { I hate getting sick. It always seems like everyone gets } \\
\text { sick as soon as it's vacation. Marguerite caught a cold } \\
\text { from Eduardo two days before Christmas. It kind of put a } \\
\text { damper on the Christmas festivities. }\end{array}$ \\
elaboration & $\begin{array}{l}\text { The professors in the music department were all in a } \\
\text { good mood. The first day of music lessons had gone un- } \\
\text { expectedly well. Melora taught a sonata to Mike in an } \\
\text { hour and a half. That is really fast. } \\
\text { related }\end{array}$ \\
$\begin{array}{l}\text { My physics class gets out at } 7 \text { pm and it's already dark } \\
\text { then. A lot of people have trouble getting home. Annette } \\
\text { usually catches a ride from Scott. I was wondering if I } \\
\text { should ask Scott to give me a ride also. }\end{array}$ \\
\hline
\end{tabular}

Table 2. Examples for each category of relation between the continuation sentence and previous one. (Participant continuation is italicized).

The results were tabulated in terms of each question. First, in what percentage of cases did people refer to the source-referent, and in what percentage to the goal-referent? Second, what was the rate of pronoun use for each type of referent? Third, how was the choice to talk about the goal or the source influenced by the choice of how the continuation sentence would relate to the rest of the story? The significance of each result was tested with a stepwise logistic regression, using SPSS 6.1. The contribution of each factor is measured in terms of the ratio of the log likelihood of a model with that factor and a model without that factor. The models can be built using either a step-up or step-down procedure; in each case I performed both analyses and found the same results. 


\subsubsection{Did Participants Begin More Often with Goal or Source- Referents?}

The first question I asked was "Who was referred to first?" Here I was interested in whether participants would begin their responses more often with references to goal- or source-referents. However, I expected that grammatical functions would interact with any effect of thematic roles. I therefore looked at the difference between goal- and source-referents separately for subject- and object-of-PP referents, calculating the proportion of references to goal- and source-referents for each category. The results are in Figure 2.

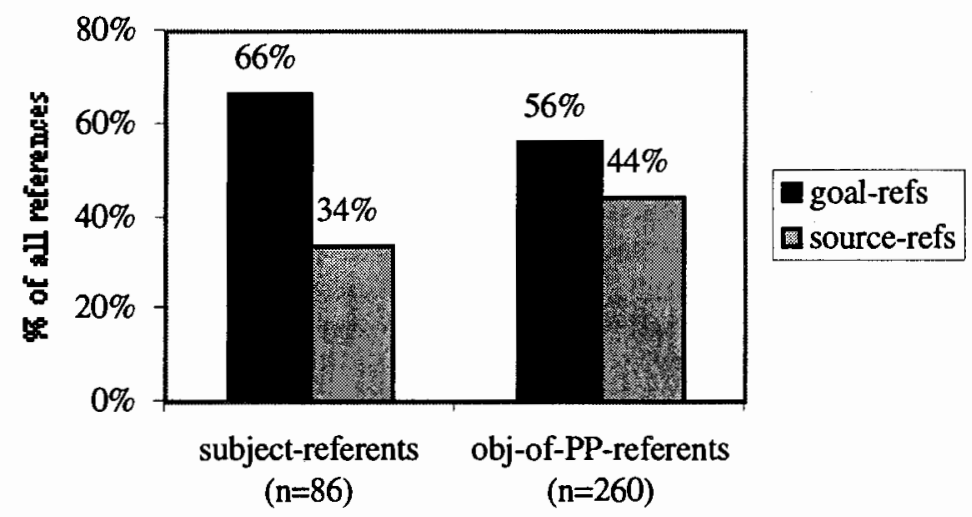

Figure 2. Distribution of choice of referent by grammatical function and thematic role.

The results revealed a goal bias for both subject referents and object-of-PP referents, in that the rate of reference to subject-referents was sensitive to verb type (goal-source vs. source-goal) $(-2 * \log \mathrm{LR}=8.467, \mathrm{df}=1, \mathrm{p}<.005) .{ }^{1}$ For

1These statistics represent an analysis that included four additional variables: 1) subject identity, 2) definiteness of theme NP, 3) presence vs. absence of end material, and 4) connection type. Subject identity was included to account for individual variation among subjects; this factor proved to account for a significant portion of the variation $\left(-2^{*} \log \mathrm{LR}=32.6, \mathrm{df}=15, \mathrm{p}<.006\right)$. Definiteness of theme NP also reliably accounted for a significant portion of the variance $(-2 * \log$ $L R=9.1, p<.005$ ), in that subjects were more likely to begin with a reference to the goal referent when the theme NP was definite. The motivation for including the other two factors (end material and connection type) will be explained later. 
both subject- and object-of-PP-referents, they were more likely to be the first referent of the continuation sentence if they were also the goal. ${ }^{2}$

The primary reason for considering who was referred to more often was to compare goal continuations with source continuations. In this regard, the experiment produced the expected results. However, a secondary, unexpected result was also observed: participants continued the discourses more often with the object-of-PP referent $(n=260)$ than the subject NP $(n=86)$. This result was surprising, because it goes against the finding that discourses are more likely to be continued with reference to subject-referents than other entities (Arnold 1999), and the more general tendency for subject-referents to be more accessible than object-referents (e.g., Gordon et al. 1993, McDonald and MacWhinney 1995, Stevenson et al. 1994).

One possible explanation of this result is that the story-completion method produces a task-specific recency effect. In normal production, recency effects are modulated by the subject bias, and speakers are more likely to refer to subject entities than object entities (Arnold 1999). This is likely to reflect the fact that subject entities tend to be more central to the discourse than object entities, perhaps because speakers tend to place more central entities in subject position. By contrast, this experiment did not reflect pure production processes, and participants were required to generate a continuation as they finished reading the stimulus. The object-of-PP character almost always appeared as the final element in the stimuli items, which may have caused it to be more activated at the point when participants were constructing their response.

The stimulus design offers a way to test this hypothesis, because in 5 of the stimuli, the object of PP did not appear as the last element in the utterance. These stimuli are shown in (4).

${ }^{2}$ For comparison I also performed an analysis that included all references to the goal or source arguments, and not just the first one. This procedure yielded more data points, because in many cases a single continuation contained references to both the source and the goal referents. These resuits followed the same pattem as the results using only the first references.

\% Proportion of references to goal and source referents, calculated separately for subject- and object-referents

\begin{tabular}{l|ll} 
& goal-referents & source-referents \\
\hline Subject-referents $(\mathrm{n}=126)$ & $68 \%$ & $32 \%$ \\
Object-of-PP-referents $(\mathrm{n}=286)$ & $56 \%$ & $44 \%$
\end{tabular}


(4) Stimulus-final sentences that contained material after the object NP.

- Marguerite caught a cold from Eduardo two days before Christmas.

- Juan received a telegram from Claire when their mother died.

- Phil paid \$200 to Emily for a full weekend.

- Melora taught a sonata to Mike in an hour and a half.

- Sam brought flowers to Ali in the hospital.

I compared the results for these items with the other items, to see if the tendency to continue with the object would disappear. There was a slightly higher tendency to refer to the subject referent in items with end material ( $35 \%$ of 37 ) than in items with no end material ( $24 \%$ of 309 ). However, the effect of end material (present vs. absent) did not reach significance when entered into the logistic regression. Therefore the corpus analysis, described below, provides an important test of whether the object-of-PP bias is a true effect, or a side-effect of the experimental methodology.

\subsubsection{Were Pronouns Used More for Goal or Source- Referents?}

I now turn to the second question, which concerns how goals and sources were referred to. I looked at four different categories of referent: subject/goalreferents, subject/source-referents, object-of-PP/goal-referents, and object-of$\mathrm{PP} /$ source-referents. For each category, I counted the percentage of cases in which pronouns were used, out of the total number of references to a referent of that type. The results, presented in Figure 3, showed that pronouns were used more for goals than sources, but the effect is most prominent for objectof-PP entities.

The data in Figure 3 reveal two patterns. First, the use of pronouns was far greater for subject referents $\left(-2^{*} \log L R=125, \mathrm{df}=1, \mathrm{p}<.0001\right)$. Second, pronouns were used more for goals than sources. However, this effect occurred primarily for object-of-PP referents, as indicated by the reliable interaction between grammatical function and thematic role $\left(-2^{*} \log \right.$ $\mathrm{LR}=4.4, \mathrm{df}=1, \mathrm{p}<.05)$. $^{3}$

${ }^{3}$ As in the previous analysis, subject identity was entered into the logistic regression to account for individual variation among subjects. This factor contributed significantly to the model $(-2 * \log L R=62, \mathrm{df}=15, \mathrm{p}<.001)$. 


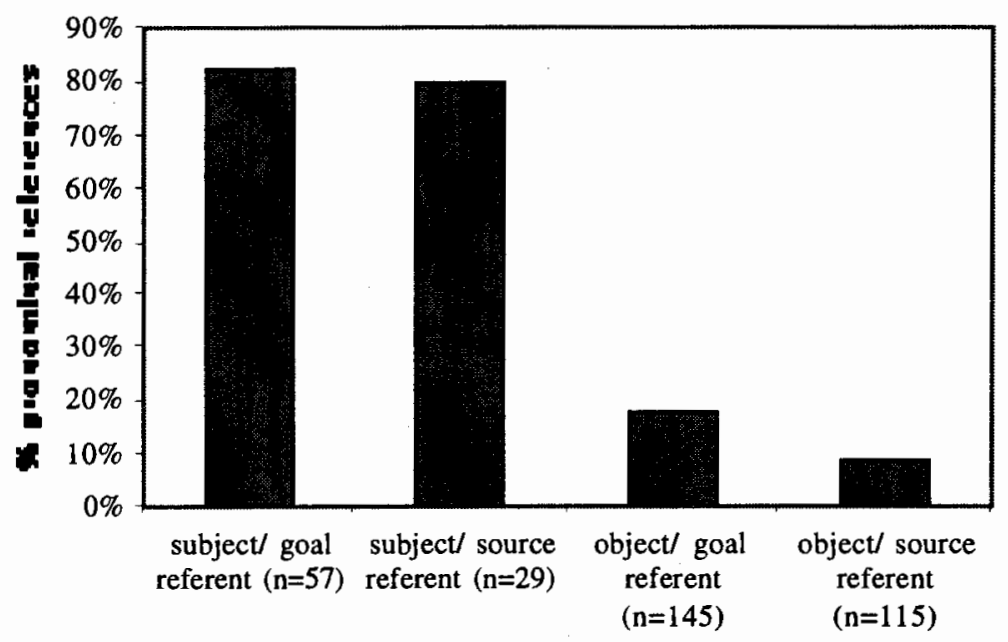

Figure 3. Percentage pronominal references by referent type.

\subsubsection{The Relationship of Continuation Sentences to the Story}

As I mentioned above, the stimuli contained no overt connectors to bias the relationship of the continuation sentence to the rest of the story. Instead, the types of continuations that people produced were the result of their reaction to other aspects of the stimuli. As participants read the stimulus story, they had to form a mental model of the characters and actions, and these mental models were influenced by the form and meaning of the three stimulus sentences.

Because this was an oral task, it was also at a rate that is close to normal speaking. Participants' responses therefore to some extent reflect the on-line processes occurring at the moment they add a continuation sentence. In particular, they reflect the cognitive status of the discourse referents, and the participants' assumptions about where the discourse is going. For example, participants may focus on a causal continuation for the story, a specification of a subsequent event, or some other type of continuation. Although the data do not reveal why they focus on one type of continuation rather than another, their responses do indicate what the type of continuation was.

Therefore, as I mentioned above, I coded each continuation sentence for continuation type. Figure 4 shows the distribution of responses across the four continuation types, considering the entire set of responses. These data 
show that the most frequent type of response (43\%) provided information about the consequences of the event.

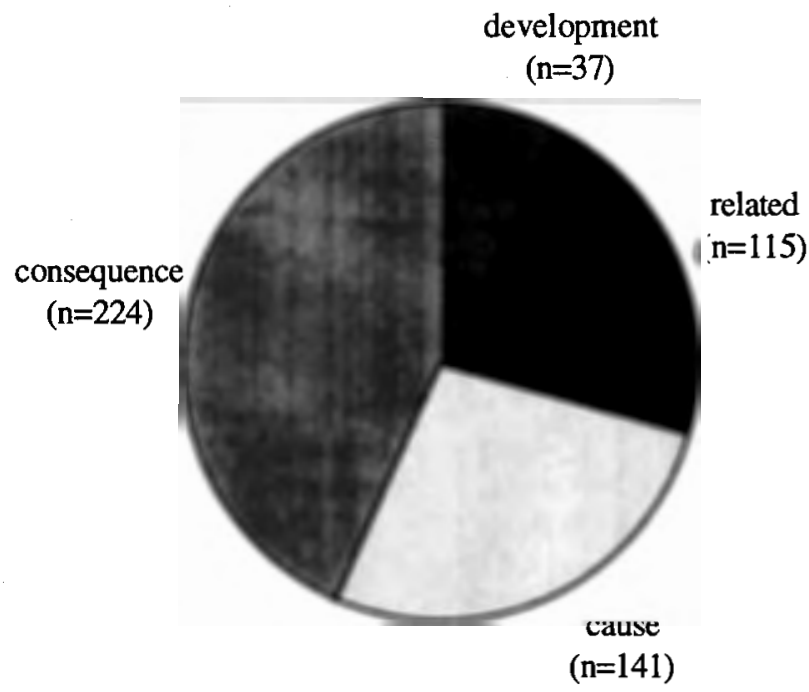

Figure 4. Percentage of all responses corresponding to each continuation type.

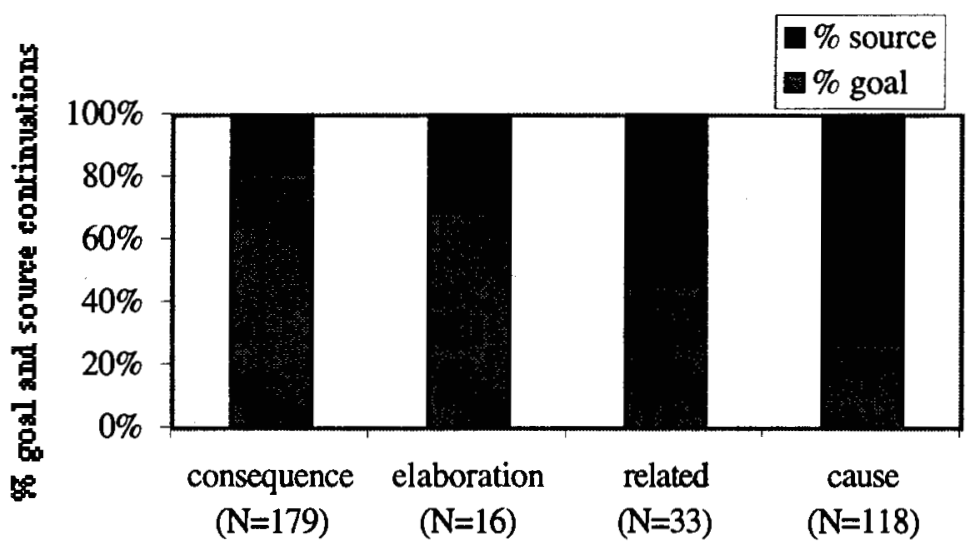

Figure 5. Proportion goal- and source- continuations in each category of thematic role and clause relationship. 
Figure 5 shows the distribution of goal- and source continuations across each of the four continuation types, which indicate that goal continuations are most common in responses that focus on the consequences. This factor contributed significantly to the logistic regression model for who was referred to first $\left(-2^{*} \log L R=42.5, \mathrm{df}=3, \mathrm{p}<.005\right)$.

\subsection{Discussion}

The results from the thematic roles experiment showed that participants tended to continue stories with goal-referents more often than sourcereferents, and also that they tended to use pronouns more often for goals than sources. The primacy of the goal-referent, in comparison with the sourcereferent, is consistent with the findings of Stevenson et al.'s (1994) written sentence completion task and Stevenson and Urbanowicz's (1995) reading time experiment. Furthermore, the results showed that participants tended to refer more often to goal referents than source referents. This suggests that the accessibility of goal referents is linked to a more general discourse pattern, whereby speakers more often focus their discourses on goals than sources.

At the same time, the results showed that the goal bias was stronger for some conditions than others. Specifically, when participants chose to explain something about the consequences of the event, they tended to talk about goal-referents more than source-referents. However, they did not always focus on the consequences, and when they didn't, the rate of reference to the goalreferent declined.

Thus, the goal bias for continuations about the consequences matched the goal bias in the full sample of continuations. The continuations about consequences were also more frequent than any other type of continuation. Therefore, the goal bias observed in the full sample may have occurred because of a bias toward focusing on the consequences of the stimulus event. In this sense, the results are consistent with Stevenson et al.'s claim that comprehenders tend to focus on the consequences of an event.

However, my results are not consistent with Stevenson et al.'s suggestion that focusing on the consequences is the default, which can be modified by connectors like because. In a task like this one, where there were no connectors, their account would predict that the large majority of responses should focus on the consequences. Contrary to this prediction, more than half of the responses did not. This suggests that these data are not best explained in terms of a default rule, an issue I will return to in section 5.

In sum, the data from the experiment showed two general patterns. People referred more to goal- than to source-referents, especially when they focused on the consequences of an event. They also used pronouns more often for goal- than source-referents. However, the results were also perplexing in one aspect: participants continued the stories with the non-subject referent 
more often than the subject referent. This contradicts the known accessibility of subject-referents, and the finding that subject-referents are more likely to be referred to again than non-subject referents (Arnold 1999). This issue was further investigated in a corpus analysis, described below.

\section{Corpus Analysis: Thematic Roles}

The purpose of this corpus analysis was to investigate patterns of discourse with respect to goal- and source-referents. Do people refer more often to referents that have played certain thematic roles?

\subsection{Methods}

I conducted a corpus analysis, using the Aligned-Hansard Corpus from 1986. The Aligned-Hansard corpus is a collection of transcripts from the Canadian Parliament, so the discourse it represents is natural and communicative, albeit formal. I extracted samples of sentences containing the verbs listed in 5 .

I only included instances where the verbs were used with both a source and a goal argument. As in the experiment, I limited the study to verbs used in the prepositional frame. I did this so that my sample of goal-source verbs would be comparable with my sample of source-goal verbs, which only occur in the prepositional frame.

(5) Verbs used in the corpus analysis

\begin{tabular}{|c|c|c|c|}
\hline \multicolumn{2}{|c|}{ SOURCE-GOAL VERBS } & \multicolumn{2}{|c|}{ GOAL-SOURCE VERBS } \\
\hline verb & \# examples & verb & \# examples \\
\hline give & 22 & get & 19 \\
\hline send & 19 & accept & 18 \\
\hline teach & 1 & receive & 25 \\
\hline offer & 20 & buy & 2 \\
\hline \multirow[t]{2}{*}{ pay } & 20 & take & 20 \\
\hline & & learn & 5 \\
\hline$\overline{\text { TOTA }}$ & 82 & & 89 \\
\hline
\end{tabular}

For each sentence in my sample, S1, I identified the next 'independent' utterance, S2. I defined 'independent utterance' as a clause which is finite, not a sentential complement of the matrix clause, and not a relative clause. I then found the first expression in S2 that referred to something from S1, if there was one, and coded whether this expression referred to the goal-referent, source-referent, or other referent from S1. Examples are shown in (6). 
(6) Examples from the thematic roles corpus analysis.

First reference

Goal (subj)

Source (subj)

Goal (obj of PP)

Other

\section{Example}

S1: We will buy what we want offshore from the United States or elsewhere.

S2: We do not have to care whether ...

S1: Individuals write, phone and visit us and all ask if we can give any assistance to them, their relatives or friends who are seeking gainful employment.

S2: We know their frustration ...

S1: Mr. Speaker, I rise today to pay special homage to a truly vibrant and magnificent lady on her sixtieth birthday.

S2: She has always had a reputation for congeniality and fairness toward all mankind.

S1: I will hasten to send this good message to the Quebec Minister of Finance.

S2: It's a comment which, I think, he will appreciate tremendously.

\subsection{Results and Discussion}

The results of this corpus analysis were tabulated separately for goal-source verbs and source-goal verbs. For each verb type, I counted the number of references to subject referents, object-of-PP referents, other referents from S1, and no referents from S1. Note that for goal-source verbs, the subject referent was also the goal-referent, and for source-goal verbs, the object-of-PP referent was also the goal-referent.

The results show that the goal-referent was mentioned more often than the source-referent $\left(\chi^{2}(1)=6.091, p<.02\right)$. Figure 6 shows the percentage of references to goal- and source-referents separately for subject- and object-ofPP-referents. The bars in Figure 6 do not add up to $100 \%$, because the percentages are calculated out of all utterances in each sample, but Figure 6 does not include the cases when S2 did not contain a reference to either the goalor source-referent. 


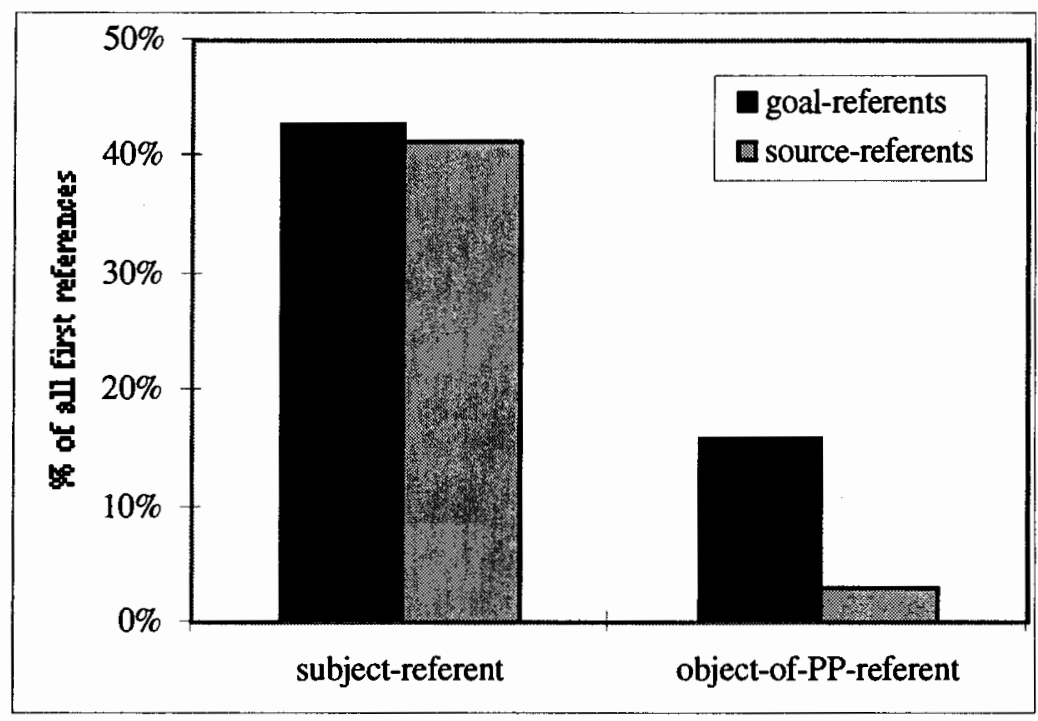

Figure 6. Corpus Analysis results: percentage of goal- and sourcecontinuations, presented separately for subject- and object-of-PPreferents.

These data show three patterns. First, there was a large effect of grammatical function. That is, speakers referred to subject referents more often than other referents. This is consistent with my findings elsewhere that subject referents get referred to more often than others (Arnold 1998, 1999). It also suggests that the object-of-PP bias in the thematic roles experiment was the result of the experimental task, and was not indicative of a tendency to focus on objects of prepositions with this type of verb.

Second, there was an effect of thematic roles. This effect is largest for the object-of-PP category, where there were more references to the goalreferent than the source-referent. This supports my hypothesis that the accessibility of goal referents is linked to the tendency for speakers to refer more often to entities that have played the role of goal. More specifically, the referents that play the role of goal are somewhat more likely to be referred to in the following utterance.

Third, there was an interaction between grammatical functions and thematic roles. That is, for subject referents, it did not matter whether the referent was also a goal or not. But for object-of-PP referents, it mattered a great deal: goal-object-referents were referred to again far more than sourceobject-referents. To test the reliability of this interaction, I considered the items with subject-referents and object-of-PP referents as separate samples, 
and asked whether the proportion of goal-referents was different in each of these two groups. I computed the z-statistic for comparing two proportions, and found that Goal Status indeed had more of an effect when the referent was also a prepositional object than when it was a subject $(\mathrm{z}=-2.09, \mathrm{p}<.05)$. This interaction is consistent with the findings about pronoun use in the experiment, as well as with Stevenson and Urbanowicz's (1995) reading time data for names and pronouns, presented in Figure 1.

\section{General Discussion}

The results of the experiment and the corpus analysis show that two generalizations can be made about verbs of transfer. First, speakers tend to talk more often about the goal- than the source-referent. Second, speakers tend to use pronouns more often to refer to the goal- than the source-referent.

In the following section, I will use these parallel findings to argue for a new framework for understanding how thematic roles influence referent accessibility and pronoun use. In $5.1 \mathrm{I}$ review some of the problems with past approaches to this issue. In 5.2 I present a multiple-constraints framework for understanding the effects of thematic roles.

\subsection{Problems with Past Accounts}

As described in section 1, past research on thematic roles an referent accessibility has focused on two factors: verb bias and overt connector words like because. Most work has proposed that the verb bias results in a focus on the implicit cause of the event (e.g., Garvey and Caramazza 1974, McDonald and MacWhinney 1995, Garnham et al. 1996). Stevenson et al. (1993) proposed instead that the verb bias varies across verb classes, such that the default bias is to focus on the consequences of an event, when the verb denotes an event. In all work, the proposed verb bias was found to vary depending on the connector word between the verb-containing clause and the pronoun-containing clause.

There are two main problems with these accounts. First, they tend to doscribe verb biases as categorical focusing strategies or default behaviors. This suggests that verb bias effects should be more homogeneous than they actually are. As shown in Figure 4, 57\% of the responses in the storycompletion experiment did not provide information about the consequences. This suggests that while these verbs do produce a tendency to focus on the consequences, this tendency is by no means a default behavior.

The second problem with these accounts concerns the role of connector words. While connector words do play a role, it is important to note that the reason they have the effect that they do is because they provide strongly constraining information about how the two clauses relate to each other. 
As comprehenders interpret a discourse, they build representations of the entities, relationships between them, and events described by the discourse. In addition, they also need to build representations of how the propositions in two consecutive clauses relate to one another. While connector words can provide strongly constraining information about what these relationships are, they are not always present. Furthermore, even when they are present, they do not provide categorical information about clause relationships. For example, the conjunction and can have many interpretations (Schmerling 1975), some of which are in (7).

(7) a. Temporal:

b. Causal:

c. Simultaneous:
I wrote my dissertation and filed it.

It was cold and she put on her jacket.

I listened to music and looked out the window.

Other connectors, like because, more strongly indicate the speaker's intentions. However, even because is ambiguous to the extent that it can signal cause in one of three domains, as in (8).

(8) a. Cause of real-world action: John came back because he loved her.

b. Cause of speaker's knowledge: John loved her, because he came back.

c. Cause of speech act: What are you doing tonight, because there's a good movie on.

(from Sweetser 1990:77)

In sum, the relationship between thematic roles and referent accessibility can not be fully described in terms of default verb biases and overt connector words.

\subsection{A Multiple-Constraints Framework}

In this section I will outline a new framework for thinking about thematic roles and referent accessibility. Here I am taking a multiple-constraints approach which has been developed to explain speech and sentence processing (e.g., MacDonald et al. 1994, Marslen-Wilson 1990, Trueswell and Tanenhaus 1994), and applying it to the explanation of discourse phenomena. Under this approach, I am assuming that language use is a dynamic process, whereby discourse referents become more or less accessible as the result of various sources of information. I use the metaphor of partial activation to describe varying levels of accessibility, where the level of activation represents the level of referent accessibility.

My proposal is centered around understanding how thematic role information can be used by comprehenders to infer how important a given referent is to the discourse. How does the comprehender know which referents the 
speaker considers more topical? Which referents are most likely to be referred to again? This inference is necessary for speakers and comprehenders to coordinate their individual models of referent accessibility in the discourse. When speakers know that comprehenders are likely to have a sufficiently activated representation of a given entity, they also know that reference resolution will be facilitated for the comprehender. When comprehension is facilitated, speakers are licensed to use underspecified forms of reference like pronouns.

Underlying this proposal is the idea that language processing involves unconscious hypotheses about where the discourse is going, and that they influence the activation of discourse referents. The listener's predictions about the discourse flow are neither conscious nor categorical. Rather, certain referents are activated probabilistically, for a short period of time, as various kinds of information become available. Activation is influenced by many sources of information, including the thematic roles of referents in the preceding clause.

\subsubsection{Pronoun Use and Frequency of Reference Continuation}

The experiment results showed that speakers use pronouns more to refer to goal referents than source referents. This finding, which is consistent with previous results about pronoun resolution (Stevenson and Urbanowicz 1995), suggests that goal referents are more accessible than source referents at the point when they are referred to. What explains this accessibility?

Given a dynamic framework for understanding language processing, the second finding from this paper offers an explanation. Both the experiment and the corpus analysis showed that speakers refer more frequently to goal referents than source referents. This indicates that from the comprehender's point of view, it is more probable that the speaker will refer to the goal referent than the source referent.

Based on this finding, I propose that the accessibility of a given referent, which can be modeled in terms of activation of its representation, is driven by the likelihood that it will be referred to again in the following discourse (either directly or through a bridging inference). When a referent is likely to be referred to again, it behooves comprehenders to instantiate a relatively activated representation of that referent in their model of the discourse. Then, if the speaker does refer to that entity again, comprehension will be facilitated.

How do comprehenders estimate the likelihood that a referent will be continued in the discourse? Here I have shown that thematic role information can be useful. In Arnold $(1998,1999)$ I also showed that factors like order of mention, parallelism, recency, and focus constructions also provide information about the likelihood for a given referent to be continued in a discourse. 
Furthermore, the data in this paper show how thematic role information interacts with order of mention: the increased likelihood for goals to be mentioned again occurs primarily for object-of-PP referents, and the pronoun preference for goals also occurs primarily for object-of-PP referents. In addition, the experimental data suggest that the likelihood for goals to be continued is influenced by the type of continuation, supporting Stevenson et al's findings that goals are most accessible when comprehenders focus on the consequences. These facts suggest that (a) thematic role biases are relatively weak, and (b) they are contingent on other factors, like the perceived contribution of the next utterance.

There are several ways the comprehender might estimate the increased probability of reference to goal entities. It might be that through experience and observation of language use, people learn that other people tend to refer to goal referents more often than source referents. ${ }^{4}$ This information could then become accessible whenever a goal referent is encountered. Alternatively, it may be that comprehenders infer this probability through a more complex evaluation of the current discourse and the particular speaker's goals.

Either way, when the comprehender can estimate a relatively high probability that a particular referent will be mentioned, this probability can be translated into a higher activation for that entity, and therefore a higher level of accessibility. If the speaker does refer to that entity, comprehension should be facilitated. In this condition, the speaker can use less specified forms of reference, like pronouns. For referents that are relatively less likely to be mentioned, their representations will receive a lower level of activation, so speakers will need to use fuller forms, like names, to refer to those entities.

There are two ways that this probability may influence the subsequent interpretation of pronouns. Some researchers have presented thematic role effects in terms of focusing (the 'focusing account'): as comprehenders determine the role of a referent in a particular event, that information influences the cognitive status of the referent, making it more, or less, accessible (e.g., Stevenson et al. 1994). During the comprehension of the next clause, referent accessibility influences the interpretation of referring forms. Other researchers have claimed that thematic role effects only come into play later, during either anaphor resolution or the integration of the anaphor with the discourse (the 'resolution/integration account'), and do not influence the representation of discourse entities beforehand (Garnham et al. 1996, McDonald and MacWhinney 1995, Stewart et al. 1998). Under either account, the discourse

${ }^{4}$ Why it is that speakers refer to goals more often than sources? The studies described here show that people do talk more about goals than sources, but they do not explain why. Speculatively, it is likely that speakers talk about goals, in particular in narrative genres, because people tend to care about the outcomes of events. 
patterns observed in the corpus analysis could play a role. Under the focusing account, the higher probability of goal referents to be mentioned again can be interpreted in terms of anticipatory activation on the representations of goal entities, before the pronoun is encountered. Under the resolution account, the activation of highly probable entities would not occur until after the anaphor has been encountered.

\subsubsection{Clause Relationship as a Multiple-Constraints Process}

As in prior work, my data suggest that the effect of verb bias is mediated by the way in which comprehenders perceive two clauses as relating to each other. By contrast with prior work, which has discussed only overt connector words, I suggest that this perception is built up dynamically during the comprehension process, and doesn't occur at any single point in time. Furthermore, it can be influenced by many constraints, of which connectors are only one.

I propose that, like referent representations, the representation of clause relationships can be thought of in terms of partial activation over representations of relationship types. At the beginning of a given clause, several relationship types might be partially activated. As the comprehender receives additional information over time, one relation will become fully activated, and the others will lose activation. Eventually only one relationship type will be selected.

What determines which relationship types are activated? As discussed above, connector words are strongly constraining, but even they do not provide completely categorical information. The influence of connector wordscan therefore be best understood as partial, probabilistic constraints. That is, a connector like because might signal a high probability that the following clause will contain causal information, and would therefore highly activate a causal interpretation. A connector like and, on the other hand, weakly activates several different relations. And provides less constraining information, leaving the listener to interpret the relationship on the basis of other factors.

Other constraints that may play a role include discourse genre, tense, or aspect. For example, (9a) may be more likely to be followed by another event than $(9 b)$.

(9) a. John raked the lawn. (Then he went inside).

b. John rakes the lawn. (But I never do).

Even though both (9a) and (9b) use the same verb, the use of the past tense in (9a) makes it more likely to be perceived as part of a narrative, in which case it is more likely that the speaker will follow up with a description of a subsequent event. In contrast, the simple present tense in (9b) turns it into a 
proposition about John's habits, which may be less likely to be followed by a description of a subsequent event.

There are several advantages to thinking of clause relationships as partial, probabilistic, and dynamic representations that are built out of several sources of information. First, it explains why participants form representations of clause relationships when connectors are not present, as in my data. Second, it explains, without relying on default processing rules, why Stevenson et al. (1994) found thematic role biases even for sentences with no connector, and why the goal bias in my data was strongest when participants focused on the consequences of the stimulus event. With no connector present, participants were influenced by other aspects of each sentence, such as the tense, aspect, genre, or, as Stevenson et al. suggest, type of verb. Third, this approach offers a more general explanation for Stevenson et al.'s finding that different biases exist for different combinations of verb types and connectors.

\section{Conclusion}

The data in this paper revealed two facts about goals and sources. First, reference to goal referents is more likely to be achieved with a pronoun than reference to source entities. Second, speakers are more likely to refer to goal referents than source referents overall. I suggested that the second finding may explain why goal-referents are more accessible than source-referents. I proposed that referent accessibility is driven by the comprehenders' estimation that a given referent will be continued in the discourse, based on their knowledge about the frequency of continuation of goal and source referents.

At the same time, these data show that the effect of thematic roles is relatively weak, compared with stronger factors like order of mention. The accessibility of goal-referents over source-referents was only measurable after controlling for grammatical function. Both the experiment and the corpus analysis also revealed an interaction, such that the effect of thematic roles on pronoun use and reference continuation is greatest for object-of-PP referents. In other words, thematic roles have an effect on referent accessibility only when other factors (i.e., order of mention effects) are less constraining.

Although there are many details to be worked out, this approach makes predictions about how other thematic roles should impact reference processing. In cases where it can be shown that speakers more frequently refer to entities that have played certain thematic roles, I would predict that both speakers and comprehenders should find pronouns more natural than fuller forms of reference. 


\section{Appendix A: Stimuli from the Story-Continuation Experiment}

\section{Goal-Source Verbs}

1. I hate getting sick. It always seems like everyone gets sick as soon as it's vacation. Marguerite caught a cold from Eduardo two days before Christmas.

2. My physics class gets out at 7 PM and it's already dark then. A lot of people have trouble getting home. Annette usually catches a ride from Scott.

3. The U2 concert was sold out a week before the show. Scalpers were selling tickets for ridiculous prices. Fortunately Rafael got a ticket from Gabrielle.

4. My high school friends really try to keep in touch with each other. It's a lot easier now that we have email. Today Gladys got three emails from Carlos.

5. Getting a telegram always scares me. It has to be either great news or awful news. Juan received a telegram from Claire when their mother died.

6. No-one was supposed to know about the lay-offs in our company. Of course, everyone did anyway. Jennifer heard the news from Pablo.

7. The high school prom was around the corner. The whole senior class had agreed to do a performance of the Macarena. Sonia quickly learned the steps from Allen.

8. The day before the exam, my whole study group was in a panic. It was 3 $\mathrm{AM}$, and no-one could figure out problem \#3. Elizabeth had to borrow the notes from Art.

9. Anyone who's anyone in Washington should be seen at the presidential inauguration. It's also really important who your date is. Courtney accepted an invitation from Bruce.

10. Our class presentation went okay, but not great. No-one in our group is a good speaker, but some are better than others. Craig should take some lessons from Pam.

11. Yesterday was probably the most exciting football game in the high school's history. A fight broke out, but not among the players-it was among the cheerleaders. It started when Blaire grabbed the megaphone from Ed.

12. My little brother and sister got into a big fight the other day. They both wanted the last piece of Halloween candy. The fight ended when Greg snatched the candy from Linda. 
13. Summer weekends are the perfect time to get away. There are many ways to travel besides cars. Last summer, Mimi rented an old bicycle from Victor.

14. It's funny how people like to point out how kids resemble their parents. But in fact it's often really striking. In my family, for example, Nick inherited big feet from Christine.

15. The amateur art show was held yesterday at the local high school. Some of the items were even for sale. Dan purchased a painting from Barb.

16. It's amazing the things you can buy used at Stanford. You can get things really cheap, especially at the end of the year when everyone is leaving. Last year Ryan bought a stereo from Delia for $\$ 50$.

\section{Source-Goal Verbs}

1. It was the final game in our company's softball tournament. The game was tied and everyone was on the edge of their seats. Fred threw the ball to Ginny.

2. The whole office was busy getting ready for the big presentation. It seemed like they would never be done. Finally Christopher handed the report to Stacy.

3. Yesterday we had our annual church picnic. We had a great game of "Toss the Egg". The best part was when Brett tossed the egg to Cathy.

4. The drama club was worried that no-one would come to the opening performance of their play. Everyone agreed to try to get all their friends to come. Erin sent an invitation to Bill.

5. Information travels fast in my school, especially gossip. When Jan and Andy broke up, everyone knew when, why, and how within days. It started when Marie told the story to Rick.

6. Yesterday our dorm's intramural basketball team played in the last game of the season. It was a big deal, because this game determined who would go to the finals. With 30 seconds to go, Holly passed the ball to Jason.

7. The students in my English class had to decide what order to give our presentations in. It was hard, because no-one wanted to go last. Tina offered the first slot to Matt.

8. The Jacksons had no trouble getting their beach house taken care of while they were on sabbatical. Lots of people offered to look after the place for them. However, Eloise had already rented the house to Andy.

9. Everyone pitched in to get the neighborhood party off the ground. Lots of people brought burgers and chicken patties. Phyllis loaned a barbecue to Wiley. 
10. The professors in the music department were all in a good mood. The first day of music lessons had gone unexpectedly well. Melora taught a sonata to Mike in an hour and a half.

11. I'll never forget the Christmas party this year. Even the shy people were dancing. Cynthia taught the lambada to Sean.

12. Everyone was shocked when the Cowan family got into a car wreck. Everyone wanted to do something to show their sympathy. Sam brought flowers to Ali in the hospital.

13. There was so much food for Thanksgiving, we didn't even eat half of it. Everyone got to take some food home. Lisa gave the leftover pie to Brendan.

14. The Donaldsons recently moved to India. They had to get rid of everything before they left. Anna sold the couch to Frank.

15. The art museum was packed when the fire broke out. Everyone can remember exactly what they were doing when the alarm sounded. Ray was showing a Van Gogh to Betty.

16. There are lots of opportunities for teenagers to make money in part-time jobs. It's possible to make quite a bit of money by babysitting. Phil paid $\$ 200$ to Emily for a full weekend.

\section{References}

Arnold, Jennifer E. 1998. Reference form and discourse patterns. Doctoral dissertation, Stanford University.

Arnold, Jennifer E. 1999. Marking salience: the similarity of topic and focus. Ms., University of Pennsylvania.

Arnold, Jennifer, Thomas Wasow, Tony Losongco and Ryan Ginstrom. In press. Heaviness vs. Newness: The effects of structural complexity and discourse status on constituent ordering. Language.

Au, Terry. K. 1986. A verb is worth a thousand words: The causes and consequences of interpersonal events implicit in language. Journal of Memory and Language, 25(1), 104-122.

Brown, Roger \& Deborah Fish. 1983. The psychological causality implicit in language. Cognition: International Journal of Cognitive Science, 14(3), 237-273.

Garnham, Alan, Matthew Traxler, Jane Oakhill and Morton Gernsbacher. 1996. The Locus of Implicit Causality Effects in Comprehension. Journal of Memory and Language, 35, 517-543.

Garvey, Catherine and Alfonso Caramazza. 1974. Implicit Causality in Verbs. Linguistic Inquiry, 5, 459-64. 
Gordon, Peter C., Barbara J. Grosz and Laura A. Gilliom. 1993. Pronouns, Names, and the Centering of Attention in Discourse. Cognitive Science 17, 311347.

MacDonald, Maryellen, Neal J. Pearlmutter and Mark S. Seidenberg. 1994. The Lexical Nature of Syntactic Ambiguity Resolution. Psychological Review 101(4), 676-703.

Marslen-Wilson, William. 1990. Activation, Competition, and Frequency in Lexical Access. In Gerry T. M. Altmann, ed., Cognitive Models of Speech Processing, 148-172. Cambridge: MIT.

McDonald, Janet and Brian MacWhinney. 1995. The Time Course of Anaphor Resolution: Effects of Implicit Verb Causality and Gender. Journal of Memory and Language, 34, 543-566.

Schmerling, Susan F. 1975. Asymmetric conjunction and rules of conversation. In P. Cole \& J. L. Morgan, eds., Syntax and semantics 3: Speech acts, 211 31. New York: Academic Press.

Stevenson, Rosemary J., Rosalind A. Crawley and Deborah Kleinman. 1994. Thematic Roles, Focus and the Representation of Events. Language and Cognitive Processes, 9(4), 473-592.

Stevenson, Rosemary J. and Agnieszka J. Urbanowicz. 1995. Structural focusing, thematic role focusing and the comprehension of pronouns. In Proceedings of the Seventeenth Annual Conference of the Cognitive Science Society, 328-333. University of Pittsburgh, PA.: LEA.

Stewart, Andrew, Martin Pickering and Anthony J. Sanford. The time-course of the influence of implicit causality information: Focus versus integration accounts. Ms., University of Glasgow.

Sweetser, Eve. 1990. From etymology to pragmatics. Cambridge: Cambridge University Press.

Trueswell, John. C. and Tanenhaus, Mike K. 1994. Towards a lexicalist framework of constraint-based syntactic ambiguity resolution. In J. C. Clifton, L. Frazier, \& K. Rayner (eds.), Perspectives on Sentence Processing, 155-179. Hillsdale, NJ: Erlbaum.

Wilson, Garry and Rosemary J. Stevenson. 1998. Do situational roles or thematic roles provide the best cues to pronoun assignment? In S. Botley and A. McEnery (eds.), New Approaches to Discourse Anaphora: Proceedings of the Second Colloquium on Discourse Anaphora and Anaphora Resolution, University Centre for Computer Corpus Research on Language Technical Papers Series, Vol. 11. Lancaster, UK: University of Lancaster Press.

Institute for Research in Cognitive Science

University of Pennsylvania

3401 Walnut St. Suite 400A

Philadelphia, PA 19104

jarnold@linc.cis.upenn.edu 